\title{
A Nasal Myoepithelioma Removed through Preoperative Embolization and Endoscopic Surgery: A Case Report and Literature Review
}

\author{
Jin Wook Kang, Sang Kwon Im, Chang Eun Song, and Su Young Jung (iD \\ Department of Otorhinolaryngology-Head and Neck Surgery, Hanyang University College of Medicine, Goyang, Korea
}

\author{
수술 전 시행한 색전술과 내시경 수술을 통해 제거된 비강 내 근상피종: 증례 보고 및 문헌 고찰 \\ 강진욱 · 임상권 · 송창은 · 정수영 \\ 한양대학교 의과대학 명지병원 이비인후과학교실
}

\author{
Received July 19, 2019 \\ Revised October 21, 2019 \\ Accepted October 23, 2019 \\ Address for correspondence \\ Su Young Jung, MD, PhD \\ Department of Otorhinolaryngology- \\ Head and Neck Surgery, \\ Myongji Hospital, Hanyang \\ University College of Medicine, \\ 55 Hwasu-ro 14beon-gil, \\ Deogyang-gu, Goyang 10475, Korea \\ Tel $+82-31-810-5114$ \\ Fax $+82-31-969-0500$ \\ E-mail monkiwh35@hanmail.net
}

\begin{abstract}
Myoepithelioma is a rare benign tumor, most frequently located in the salivary gland. However, involvement of an extra-salivary gland is even rarer and very few cases involving the nasal cavity have been reported in the literature. A 51-year-old female patient presented with a complaint of progressive nasal obstruction and occurrence of recurrent epistaxis in the left nasal cavity over several months. A hemorrhagic and erythematous mass occupying the left nasal cavity was observed on physical examination using a nasal endoscope. A preoperative angiogram confirmed that he tumor was receiving blood supply from the sphenopalatine artery. We performed embolization to prevent hemorrhage during surgery; one day later, the lesion was successfully removed through endoscopic excision. Histopathological examination revealed that the tumor contained myoepithelial cells and myxoid stroma. Immunohistochemical studies showed that the tumor was positive for cytokeratin marker and S-100 protein, confirming the diagnosis of myoepithelioma. The patient recovered without any nasal symptoms or postoperative deficits. Korean J Otorhinolaryngol-Head Neck Surg 2019;62(12):747-54
\end{abstract}

Key Words Chemical embolization · Myoepithelioma · Nasal cavity.

\section{Introduction}

Myoepithelioma was first reported by Sheldon in 1943 and is a benign tumor mostly composed of myoepithelial cells. ${ }^{1)}$ Most myoepitheliomas manifest as a mass that slowly increases in size without causing other symptoms. ${ }^{1)}$ Myoepitheliomas generally develop in the salivary gland, but they are rare and only account for only $1 \%$ of all tumors originating from the salivary gland. It can occur in both major and minor salivary glands, but most often develops in the parotid glands. ${ }^{1-4)}$ Involvement of extra-salivary glands is extremely rare, and only a few

This is an Open Access article distributed under the terms of the Creative Commons Attribution Non-Commercial License (https://creativecommons.org/licenses/by-nc/4.0) which permits unrestricted non-commercial use, distribution, and reproduction in any medium, provided the original work is properly cited. cases have been reported in unusual locations such as the breast, lacrimal gland, lung, trachea, nasopharynx, middle ear, external auditory canal, nose, and paranasal sinuses. ${ }^{2-15)}$ In this report, we present a case of myoepithelioma of the left nasal cavity treated with preoperative embolization and endoscopic surgical excision. To the best of our knowledge, there are have been only 11 reports of myoepithelioma in the nasal cavity or paranasal sinuses in the English-language literature up until $2019 .^{2-15)}$

\section{Case}

A 51-year-old woman presented to the department of otorhinolaryngology-head and neck surgery outpatient clinic, 
with a history of nasal obstruction and recurrent epistaxis in the left nasal cavity for several months. During the visit, a physical examination using nasal endoscopy revealed a large mass with hemorrhagic and erythematous mucosa occupying the left nasal cavity (Fig. 1A). A CT scan revealed a heterogenous low density mass formed from soft tissue in the left nasal cavity. Anterior ethmoid cells were visible with moderate enhancement using a contrast medium (Fig. 2). MRI also showed a tumor located in the nasal cavity. The mass was predominantly hypointense with small hyperintense structures on T1-weighted images (Fig. 3A). The mass was heterogeneously hyperintense on T2-weighted images (Fig. 3B). T1-weighted imaging with gadolinium showed overall moderate enhancement of mass (Fig. 3C).

An angiogram was performed the day before surgery and blood supply from the left sphenopalatine artery to the tumor in the nasal cavity was confirmed (Fig. 4A). During this procedure, chemical embolization was performed to prevent bleeding during surgery by infusing small and irregular flakes of polyvinyl alcohol (Fig. 4B).

The tumor was completely resected with an appropriate safety margin during endoscopic surgery. The surface of the tumor looked like normal nasal mucosa. Keeping the mass intact during removal was difficult because of its size; therefore, it had to be removed in pieces. The septal cartilage, adjacent to the tumor, had been partially absorbed due to mechanical pressure. The inferior and middle turbinate were reduced in size, but the mucosa was intact. The tumor originated from the middle part of the left nasal septum (Fig. 1B).

Histopathologically, the tumor was composed mostly of spindle cells occurring in sheets or swirls and loose clusters of plasmacytoid cells. The stroma was either collagenous or myxoid.
No mitosis was present (Fig. 5A). Immunohistochemical studies revealed that the mass was positive for cytokeratin markers and the S-100 protein (Fig. 5B and C). These results were consistent with a myoepithelioma. The patient was followed up for 1 year after surgery, and there was no evidence of recurrence of the mass in the nasal cavity (Fig. 1C).

\section{Discussion}

Myoepithelioma is a rare benign neoplasm that originates from the salivary glands. It has now been classified as an individual disease entity by the World Health Organization (WHO). ${ }^{1)}$ The tumor is composed of myoepithelial cells, which vary considerably in appearance, both in architecture and cytology. These cells are present in many secretory organs and have a dual epithelial and smooth muscle phenotype. The pattern of growth may be solid, myxoid, or reticular, and the cells themselves may be plasmacytoid, spindle-shaped, or a mixture of the two. Salivary glands have these cells in their acini and intercalated ducts and these cells form an important component in many kinds of neoplasms derived from the salivary glands. ${ }^{3)}$ Myoepitheli-
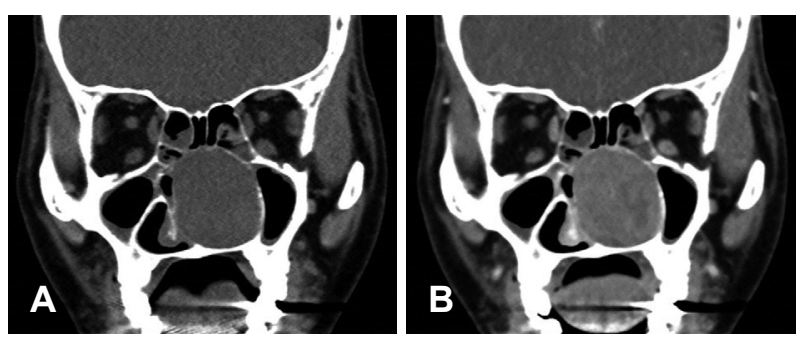

Fig. 2. Preoperative CT scan. Coronal CT scan showing that the bone of the medial maxillary wall is preserved and lateralized $(A)$. Coronal CT scan with contrast that shows that there was no distinct staining of the tumor $(B)$.
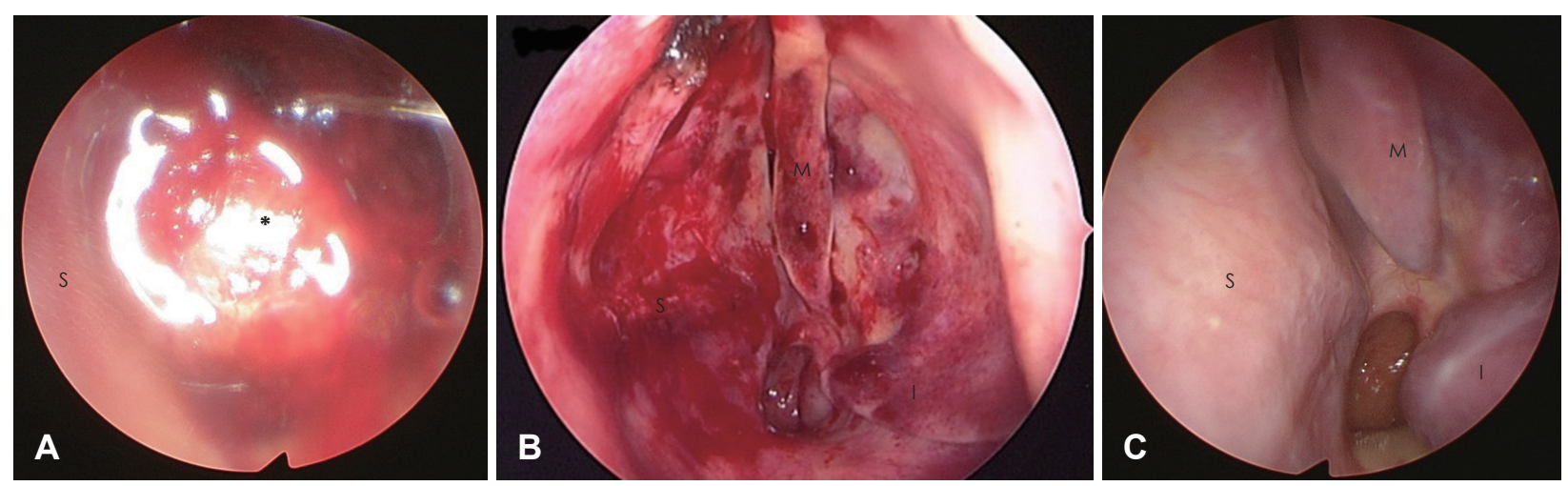

Fig. 1. Nasal endoscopic view at the initial visit. The tumor, with mild hemorrhage and erythematous mucosa, filled the left nasal cavity (A). Endoscopic view immediately after resection. The origin of the mass was the middle part of the nasal septum. The septum was deviated to the contralateral side of the mass. The inferior and middle turbinate were reduced in size due to compression from the mass (B). Endoscopic view 1 year after the operation. There was no sign of recurrence $(C)$. S: septum, M: middle turbinate, I: inferior turbinate, Asterisk: tumor. 

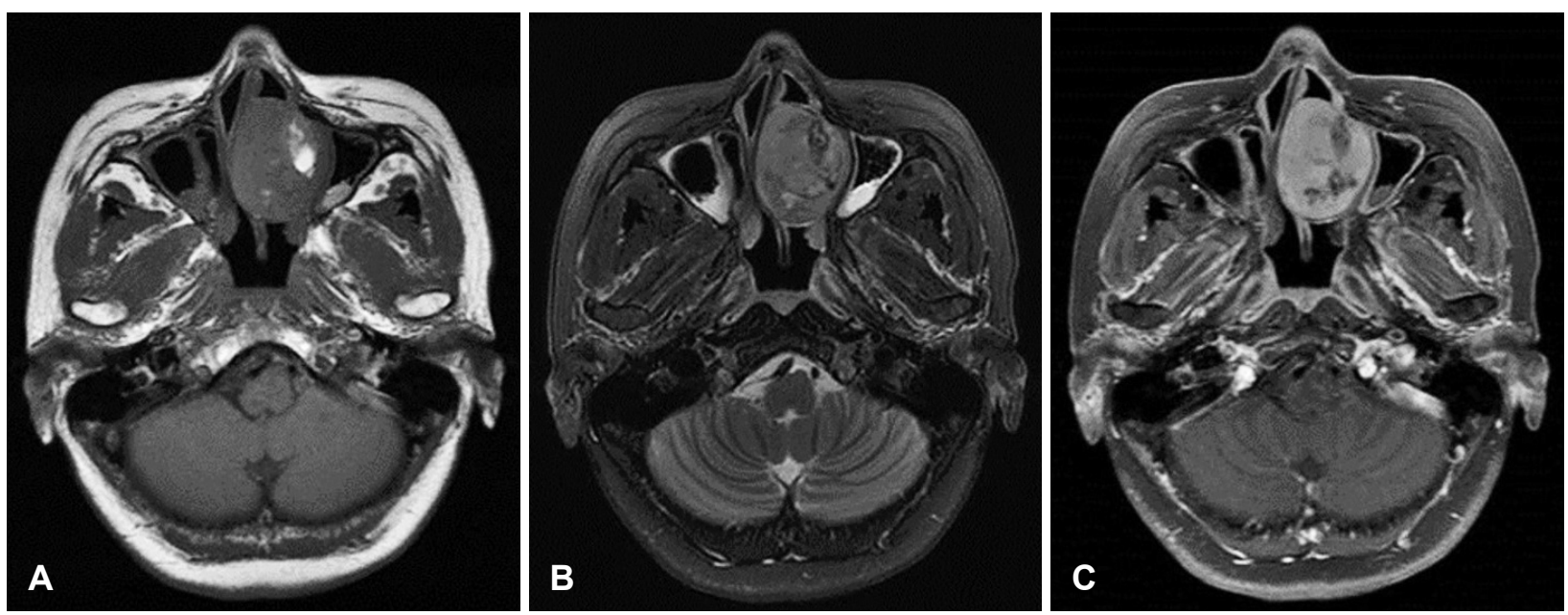

Fig. 3. Preoperative MRI. Axial T1-weighted image showing a hypointense lesion occupying the left nasal cavity. A partially hyperintense area is seen on the lateral side of the mass $(A)$. Axial T2-weighted image showing a heterogenous tumor with an intermediate region (B). T1-weighted imaging with gadolinium showing overall enhancement (C).
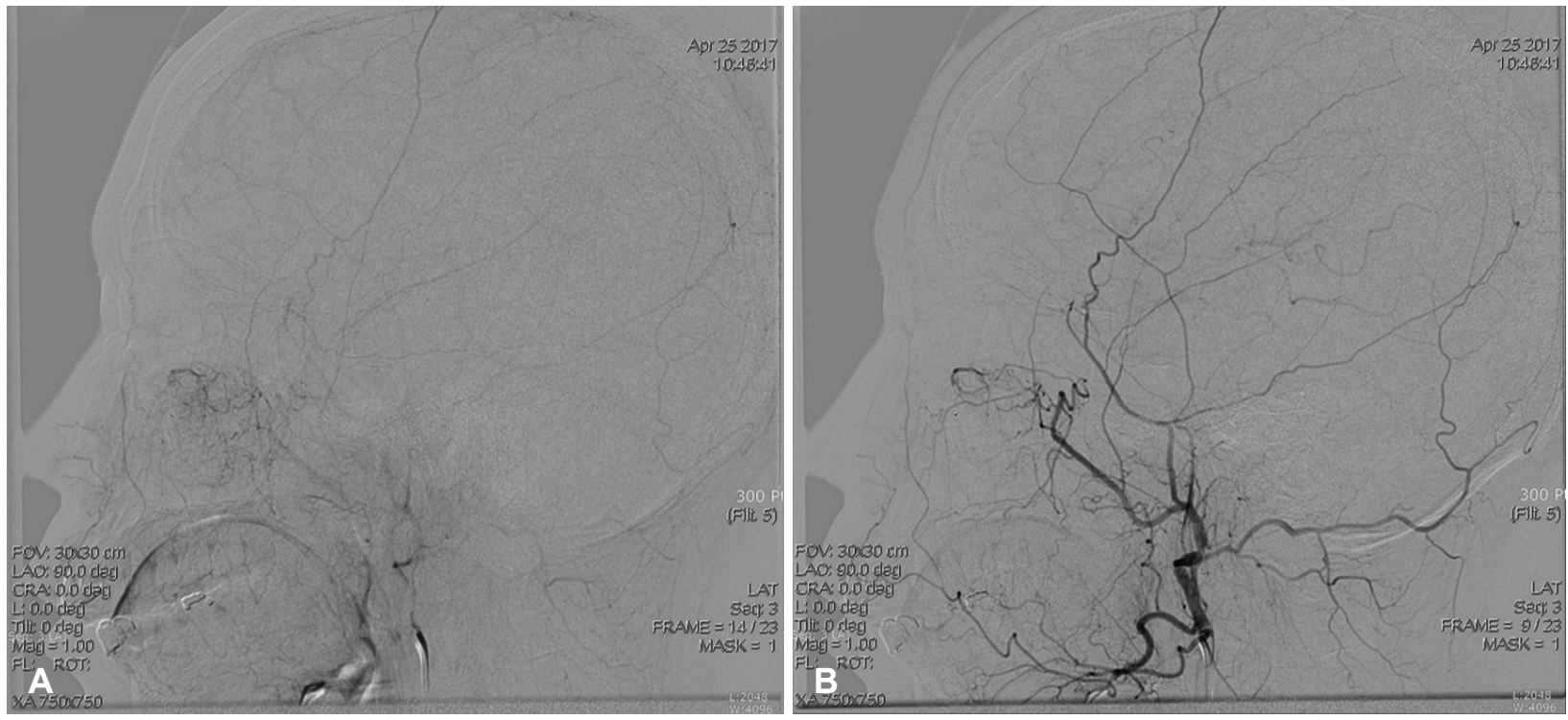

Fig. 4. Preoperative angiogram. The stain of a hyper-vascular tumor in the left nasal septum before embolization during preoperative angiogram (A). The feeding arteries of the tumor were successfully occluded after embolization and post-procedural angiogram confirms disappearance of the tumor stain (B).
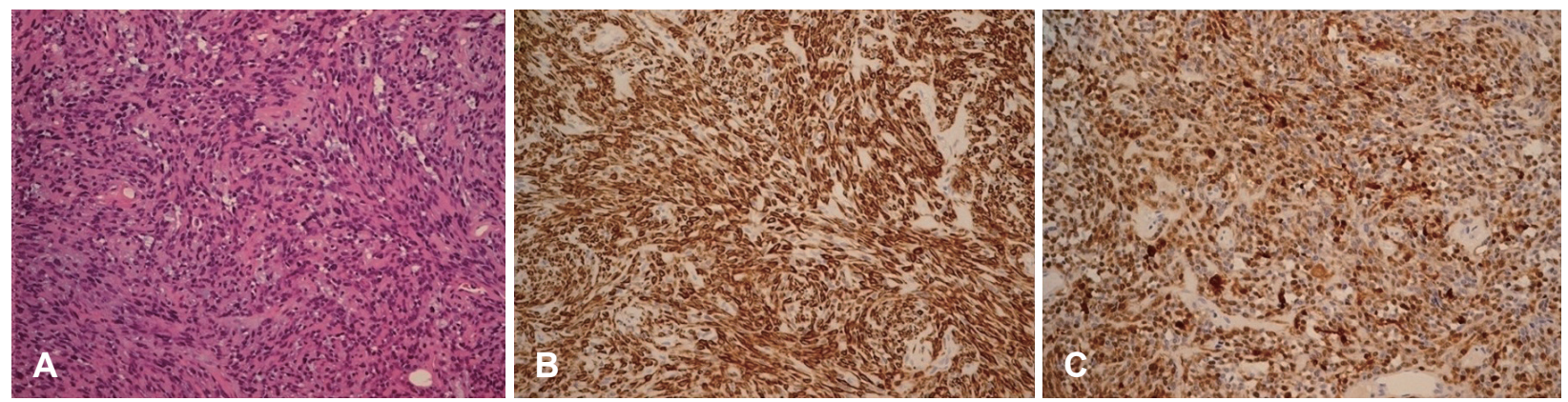

Fig. 5. Microscopic view. Histopathological findings. Typical plasmacytoid myoepithelial cells among myxoid stroma. Hematoxylin and eosin staining, $\times 400(A)$. Immunohistochemical studies (B and C, $\times 200$ ). Positive staining for S-100 protein (B) and $\alpha-S M A(C) . \alpha-S M A$ : $\alpha$-smooth muscle actin. 
omas may also contain a small number of ducts within sheet of the neoplastic myoepithelial cells. Thus, myoepithelioma is likely to constitute one end of the biological spectrum that includes pleomorphic adenoma and basal cell adenoma. ${ }^{13)}$ The differential diagnosis of myoepithelioma must include pleomorphic adenoma. This is supported by the fact that they are very similar in terms of biological processes, distribution, morphology, and even immunohistochemistry. In fact, the criteria for distinguishing between these lesions are primarily subjective. The WHO suggests that if a neoplasm contains less than $5 \%$ ductal components, it should be diagnosed as a myoepithelioma. ${ }^{1,13)}$ In our case, ductal components and mitosis were rarely observed, and vascular invasion was not present histologically.

Salivary gland tumors account for $2-4 \%$ of all head and neck tumors. ${ }^{1)}$ Most salivary gland tumors originate from the parotid gland (almost 70\%). The remaining tumors arise from the minor salivary glands (approximately 22\%) and the submandibular glands (almost $8 \%$ ). The most frequently affected location is the oral cavity; however, these tumors are rarely found in the nasal cavity. These tumors could originate from the minor mucous and serous glands, which are mostly located on the lateral nasal wall; misplaced embryonic epithelial cells; or remnants of the vomeronasal organ, an epitheliumlined duct in the septum that degenerates in early fetal life. ${ }^{1,7)}$ Therefore, an additional immunohistochemical stain should be performed to clearly diagnose myoepithelioma. Immunohistochemistry is necessary to confirm the diagnosis, and stains are typically positive for cytokeratin, S-100, calponin, $\alpha$-smooth muscle actin ( $\alpha$-SMA), myosin, vimentin, glial fibrillary acidic protein, and carcinoembryonic antigen. ${ }^{6,11)}$ The main marker for myoepithelioma is the $\mathrm{S}-100$ protein and a diagnosis will rarely be made if this stain is negative. ${ }^{1)}$ In our case, S-100 protein and $\alpha$-SMA staining were both positive.

On a CT scan, this neoplasm appears isodense to muscle and demonstrates a moderate homogenous enhancement with contrast; on T1-weighted MRI, it is hypointense and displays a dense, homogenous enhancement. In our case, similar findings were observed in these 2 imaging tests. However, these CT and MRI findings are not specific to myoepithelioma. Nonetheless, as seen in most cases, CT and/or MRI are valuable tests when determining the optimum therapeutic plan. Preoperatively, the presented case was considered to be a benign tumor because of the normal mucosa appearance on nasal endoscopy and was well demarcated on CT and MRI. The tumor also needed to be differentiated from other benign tumors that have a tendency to bleed, such as angiofibroma and hemangioma. Preoperative chemical embolization was performed. Based on all the preoperative findings, the tumor was resected endoscopically. According to one study, using preoperative embolization as part of the treatment for angiofibroma reduces intraoperative blood loss was reduced by approximately $40 \%$; and in another study, intraoperative blood loss was reduced by more than $60 \%{ }^{14,15)}$ Therefore, preoperative chemical embolization could be useful if the preoperative diagnosis is not accurate.

Myoepithelioma of the nasal cavity is an extremely rare tumor, with only 11 cases reported in the literature so far (Table 1). Out of a total of 11 patients, 4 (36.4\%) were male, and 7 $(63.6 \%)$ were female. Our case report was also of a female patient. However, more cases are needed to establish any sex differences associated with myoepithelioma of the nasal cavity. Of the 11 cases reported in the literature, most patients complained of nonspecific symptoms, such as a history of nasal obstruction that had been ongoing over several months, minor epistaxis, and a painless mass in the nasal cavity. ${ }^{2-9,11,12)}$ Only 1 patient reported aggressive symptoms such as facial asymmetry or severe facial pain. ${ }^{10)}$ In agreement with the cases reported in the literature, the patient in our case report also complained of nasal obstruction of the left nasal cavity lasting several months and recurrent epistaxis. However, these are also symptoms of other benign tumorous lesions of the nasal cavity. Therefore, a preliminary diagnosis of myoepithelioma based on these symptoms alone has its limitations. Myoepithelioma in the nasal cavity detected during physical examination is seen as a tumor with relatively healthy mucous membranes, which have a clear boundary separating them from the surrounding area. In some reports, hemorrhagic irregular vascular lesions were seen, as in our case. ${ }^{8,11)}$ In most cases, the tumor is localized within the nasal cavity or sinus; rarely, hard palate bulging has been reported. ${ }^{10)}$ However, since the number of cases reported is insufficient, it is not possible to define the features of myoepithelioma through these endoscopic findings.

Except for 2 patients who refused surgery for personal reasons, ${ }^{4,5)} 9$ cases involved surgical excision. They did not show any signs of recurrence or any associated sequelae during the 6-80-month follow-up period. Of those 9 cases, 4 (44.4\%) involved surgical excision with an external approach, and 5 (55.6\%) involved endoscopic surgical excision. ${ }^{9}$ The present case of myoepithelioma of the left nasal cavity was located in the middle part of the nasal septum and was treated using preoperative chemical embolization and endoscopic excision. 


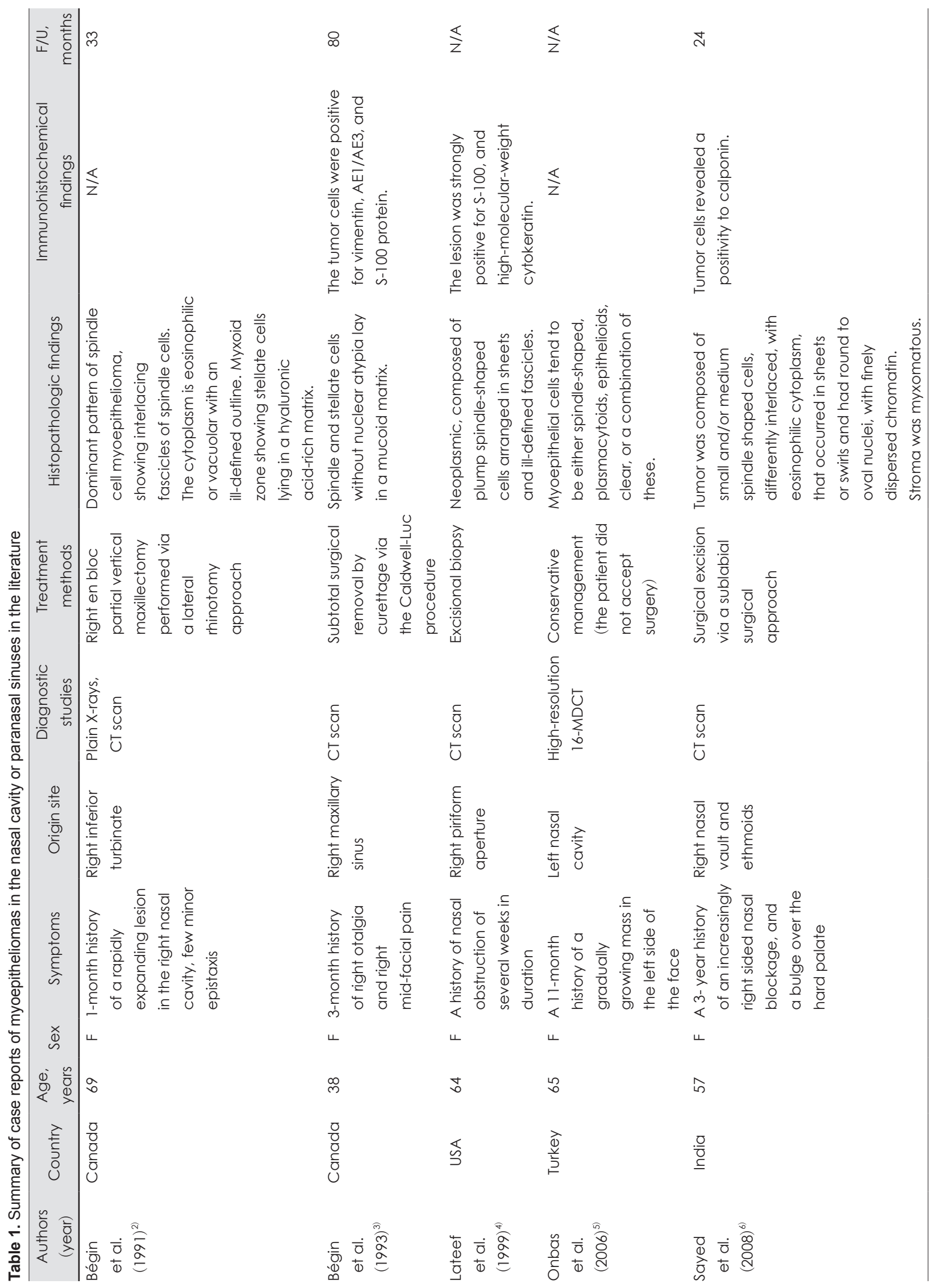




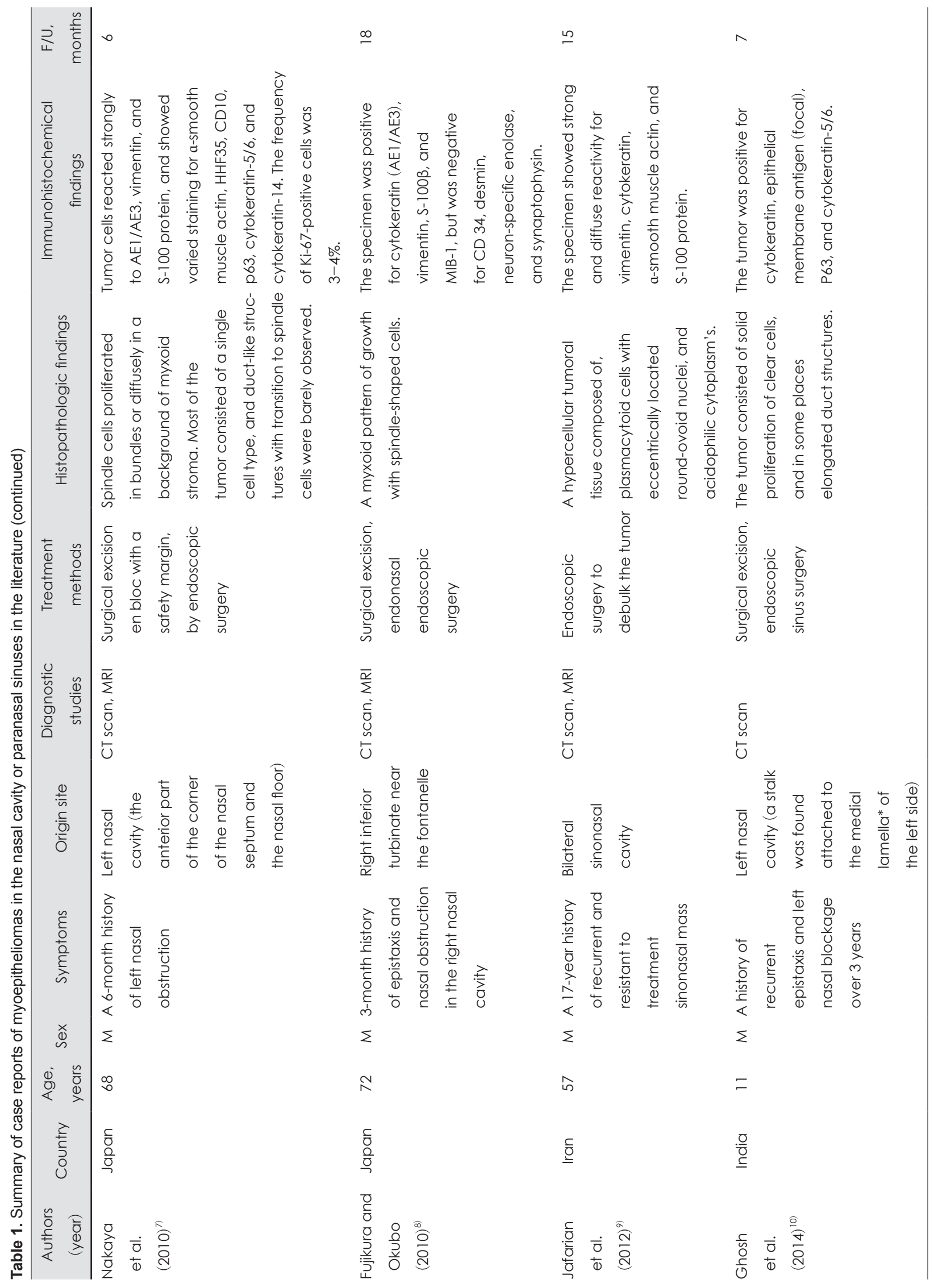




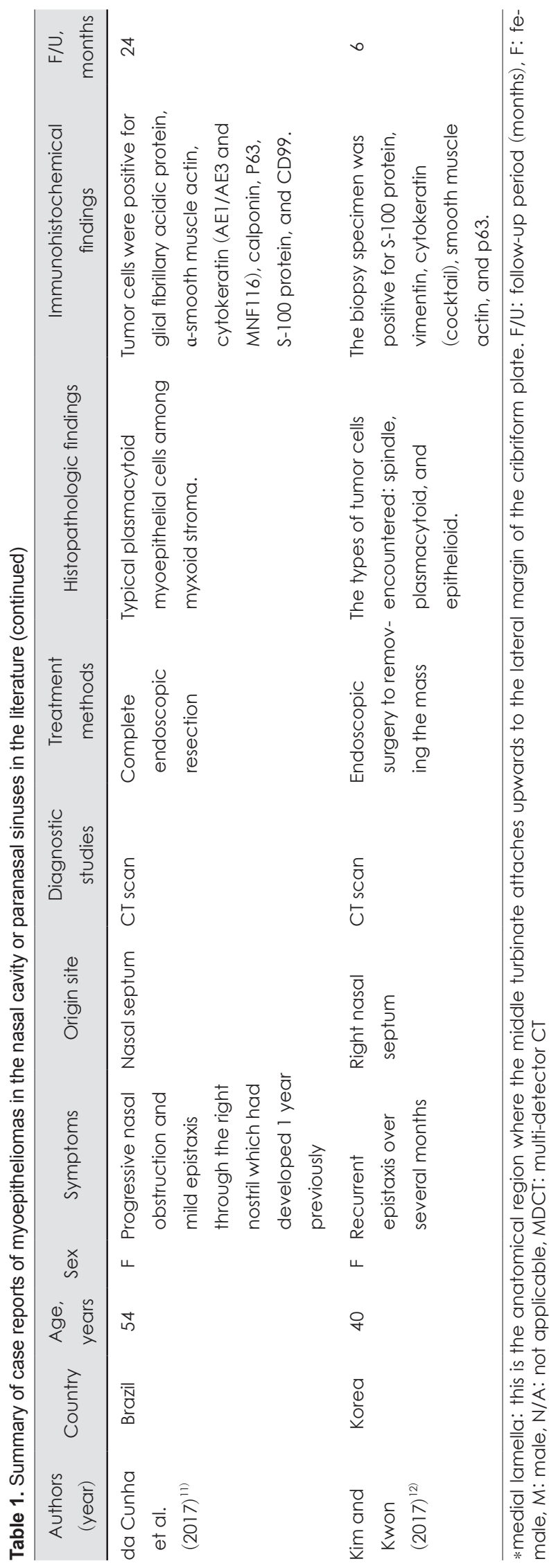

There was no evidence of recurrence in the nasal cavity during the follow-up period. Based on these results, surgical excision should be considered as a treatment method for myoepithelioma in the nasal cavity.

Conventional myoepitheliomas and pleomorphic adenomas have comparable aggressiveness, and recurrence of conventional myoepitheliomas is rare. However, there have been cases with more than 6 recurrencess in a 17-year period," where recurrence was related to the margins of the initial resection. Therefore, it is necessary to confirm that the excision margin is negative following careful histological examination of the specimen removed by surgical excision. In our case, the excision margin was negative. Although rare, there is a possibility of recurrence; ${ }^{99}$ therefore, regular follow-ups after surgery is required.

Myoepithelioma in the nasal cavity is an extremely rare benign tumor. However, over the past few years, the number of reports of extra-salivary gland involvement have increased significantly. Advances in pathology and immunohistochemistry knowledge and techniques can help us to accurately diagnose this tumor more often in the future. It is necessary to consider the possibility of myoepithelioma when diagnosing benign tumors in the nasal cavity.

\section{Acknowledgments}

This research did not receive any specific grant from funding agencies in the public, commercial, or not-for-profit sectors.

\section{ORCID}

Su Young Jung https://orcid.org/0000-0001-6398-1297

\section{REFERENCES}

1) Barnes L, Appel BN, Perez H, El-Attar AM. Myoepithelioma of the head and neck: Case report and review. J Surg Oncol 1985; 28(1):21-8.

2) Bégin LR, Rochon L, Frenkiel S. Spindle cell myoepithelioma of the nasal cavity. Am J Surg Pathol 1991;15(2):184-90.

3) Bégin LR, Black MJ. Salivary-type myxoid myoepithelioma of the sinonasal tract: A potential diagnostic pitfall. Histopathology 1993;23(3):283-5.

4) Lateef SS, Castillo M, Mukherji SK, Cooper LL. Myoepithelioma of the nasal piriform aperture: CT findings. AJR Am J Roentgenol 1999;173(5):1413-4.

5) Onbas O, Karasen RM, Gursan N, Kantarci M, Alper F, Okur A. Giant myoepithelioma of the face: MDCT with 2D and 3D images. AJR Am J Roentgenol 2006;187(4):W418-9.

6) Sayed SI, Kazi RA, Jagade MV, Palav RS, Shinde VV, Pawar PV. A rare myoepithelioma of the sinonasal cavity: Case report. Cases J 2008;1(1):29.

7) Nakaya K, Oshima T, Watanabe M, Hidaka H, Kikuchi T, Higashi $\mathrm{K}$, et al. A case of myoepithelioma of the nasal cavity. Auris Nasus Larynx 2010;37(5):640-3.

8) Fujikura T, Okubo K. Nasal myoepithelioma removed through 
endonasal endoscopic surgery: A case report. J Nippon Med Sch 2010;77(5):273-6.

9) Jafarian AH, Omidi AA, Roshan NM, Montazer M, Joushan B. Recurrent extensive plasmacytoid myoepithelioma of the sinonasal cavity. J Res Med Sci 2012;17(10):979-82.

10) Ghosh A, Saha S, Pal S. Myoepithelial neoplasm of nasal cavity: An uncommon tumor presenting with an unusual clinical presentation. Kulak Burun Bogaz Ihtis Derg 2014;24(1):42-5.

11) da Cunha GB, Camurugy TC, Ribeiro TC, Costa NN, Azevedo AC, Vinhaes ES, et al. Myoepithelioma of the nasal septum: A rare case of extrasalivary gland involvement. Case Rep Otolaryngol 2017;
2017:7057989.

12) Kim SB, Kwon JH. Myoepithelioma of the nasal septum. J Craniofac Surg 2017;28(7):e653-4.

13) Simpson RH, Jones H, Beasley P. Benign myoepithelioma of the salivary glands: A true entity? Histopathology 1995;27(1):1-9.

14) Li JR, Qian J, Shan XZ, Wang L. Evaluation of the effectiveness of preoperative embolization in surgery for nasopharyngeal angiofibroma. Eur Arch Otorhinolaryngol 1998;255(8):430-2.

15) Siniluoto TM, Luotonen JP, Tikkakoski TA, Leinonen AS, Jokinen $\mathrm{KE}$. Value of pre-operative embolization in surgery for nasopharyngeal angiofibroma. J Laryngol Otol 1993;107(6):514-21. 